\title{
How Users Search the Library from a Single Search Box
}

\author{
Cory Lown, Tito Sierra, and Josh Boyer
}

\begin{abstract}
Academic libraries are turning increasingly to unified search solutions to simplify search and discovery of library resources. Unfortunately, very little research has been published on library user search behavior in single search box environments. This study examines how users search a large public university library using a prominent, single search box on the library website. The article examines two semesters of real-world data, totaling nearly 1.4 million transactions. Findings include that unified library search is about more than the catalog and articles, though these predominate. Additionally, a small number of the most popular search queries accounts for a disproportionate amount of the overall queries. Also discussed are the merits of ongoing evaluation of library user search behavior.
\end{abstract}

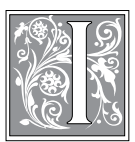

$\mathrm{t}$ is nearly impossible to discuss search and discovery in libraries without mentioning Google. The search engine has shaped user expectations for ease of use and accentuated by contrast the challenges library users encounter when they use library websites to search for information. ${ }^{1}$ The fragmented state of search and discovery on library websites results in part from what Lorcan Dempsey identified as the complexity of the library systems environment, which includes purchased materials (items managed by the integrated library system [ILS]), licensed materials (electronic journals and article databases), digital resources (institutional repositories, special collections resources), and the library's website. ${ }^{2}$ Rather than being organized by research needs and user expectations, library information resources have traditionally been organized by the disparate systems library organizations use to manage those resources.

Although libraries aspire to provide effective and easy-to-use search interfaces, they have achieved mixed success. Much work has been devoted to improving library catalog search interfaces. Attention given to uncovering problems people encounter in the online catalog has led to the addition of features such as keyword searching, relevance ranked results, and faceted browsing. ${ }^{3}$ These modernizations make catalogs easier to use, but fail to address the broader discovery problem: that the catalog typically exposes only resources managed by the ILS. However advanced in appearance and features, the next-generation catalog cannot help users discover resources or information

Cory Lown is Digital Technologies Development Librarian, e-mail: cory_lown@ncsu.edu; Josh Boyer is Head, User Experience at NCSU Libraries, e-mail: josh_boyer@ncsu.edu; Tito Sierra is Associate Director for Technology at MIT Libraries, e-mail: tjsierra@mit.edu. (C2013 Cory Lown, Tito Sierra, and Josh Boyer, Attribution-NonCommercial (http://creativecommons.org/licenses/by-nc/3.0/) CC BY-NC 
not managed by the ILS, such as links to journal articles or specialized research databases.

Libraries have attempted to make article searching easier for users by implementing metasearch systems, which combine results from multiple databases into a single interface. Unfortunately, metasearch implementations fall short of their potential to improve the library search environment. Commonly cited shortcomings include: slow response time ${ }^{4}$ incomplete coverage of important databases (Warren estimated that as many as 38 percent of important resources would be excluded from a metasearch), ${ }^{5}$ and limited search interfaces that obscure advances made to native database search interfaces. ${ }^{6}$ More fundamentally, however, metasearch systems are yet another resource in the information environment users have to understand. As Cervone noted, "the term 'metasearch' means absolutely nothing to most people." ${ }^{7}$ Warren worried that, despite the theoretical promise of a simplified research environment, "clumsy metasearching implementations will drive frustrated users more quickly to Google (and Google Scholar) and away from subscription library databases," precisely opposite the intended effect. ${ }^{8}$ The objective of metasearch is laudable: to provide library users with an easier way to search for articles. The failure of metasearch to live up to its promise demonstrates the importance of making systems that are comprehensible and user friendly.

More recently, libraries have turned to discovery platforms, such as WorldCat Local and Summon, with large, aggregated indexes to provide users with a better search experience. Discovery platforms differ from metasearch by using a centralized search index that makes them more responsive and more similar to common search environments on the web, such as e-commerce sites and web search engines. ${ }^{9}$ The inclusion of library catalog holdings, journal articles, newspaper articles, e-books, and other material in discovery platforms is also a welcome step toward dismantling systems-level barriers between resources. Way's 2010 study of use data before and after implementing Summon at Grand Valley State University observed a "sharp decline in database use combined with a steep increase in full-text downloads and linkresolver click-throughs." ${ }^{10}$ He concluded that "Summon had a dramatic impact on user behavior and the use of library collections." ${ }^{11}$

Even the most optimistic portraits of discovery platforms, however, hint at shortcomings. These include lack of all but the most basic interface customization, lack of complete coverage of all library resources, high cost, and some usability problems. ${ }^{12}$ It is also uncertain where discovery platforms fit among the broader set of information resources that libraries provide. Inexperienced library users already struggle to disambiguate various types of resources. ${ }^{13}$ Further research is needed to determine whether combining heterogeneous resource results into a single results list helps or hinders library users as they navigate the library resource environment. Libraries must think carefully about how to present discovery platforms along with everything else they provide, including those tools that overlap in functionality, such as the catalog and specialized article databases.

Because discovery platforms combine a wide range of information resources into a single index, some libraries have started to feature them prominently as the default search tool on their websites. Indeed, enthusiasm about discovery platforms led Wisniewski to declare that they "finally [get] us to a true single search."14 There is little research available, however, to indicate how discovery platforms perform when they are featured as the primary search engine on library websites.

Evidence shows that a prominent, primary search box elicits significant user expectations and will attract use. Teague-Rector and Ghaphery found that 
increasing the size and prominence of the search box on the Virginia Commonwealth University Libraries home page resulted in a nearly 100 percent increase in the number of searches from that page. ${ }^{15}$ Because prominent search boxes attract high use, it is especially important to consider problems users encounter when the capability of the search box does not meet their expectations. Teague-Rector and Ghaphery caution that a "larger, more visible search box may lead users to falsely assume that the library search functions like an online search engine."16 Swanson and Green found in a library website usability study that:

The search box became an obstacle in [...] questions where it should not have been used. In some cases, the search box was viewed as an all-encompassing search of the entire site. Several students searched for administrative information, research guides, and podcasts in this box. ${ }^{17}$

In a 2002 article reporting on a website usability study, Augustine and Greene noted that students seemed drawn to use the library's website search box whether or not it was appropriate for the task. ${ }^{18}$ In addition to causing frustration, a search box that misses a wide swath of available information and resources will make that missing information practically invisible. ${ }^{19}$ When considering whether to position discovery platforms as the primary search interface to libraries, it is vital to understand whether their performance is adequate for how users search.

Libraries are typically required to choose whether the primary search box on their website will by default search the catalog, an article database, or the library website..$^{20}$ Multiple search boxes, tabbed search boxes, or a single box with selectable targets are methods that libraries have used to direct search traffic appropriately. Teague-Rector and Ghaphery's analysis of user behavior with different search target selector designs found that the default option (in this case, the cata$\log$ ) received high use whether presented in tabs $(60.5 \%$ of use) or drop-down selectors (72.4\% of use). ${ }^{21}$ Similarly, during the three months of summer 2011, the NCSU Libraries observed that the default search box, labeled "All" in figure 1, was used for 73.7 percent of searches from the home page. The other tabs were used less frequently, with the articles, catalog (labeled "Books \& Media"), and website tabs receiving 11.7 percent, 13.5 percent, and 1.1 percent of use, respectively. While this distribution could change as we collect more data, it does indicate that the stakes are high to ensure that the default search option performs well. Although libraries may be inclined to design their home pages around a single search box to give an impression of simplicity, inadequate functionality and resource coverage may frustrate users and hide significant portions of library resources and services.

There are few obvious patterns or strategies libraries can employ to provide users with effective and understandable search environments. In a 2008 survey of how search is implemented on library websites, Ghaphery, Teague-Rector, and Byrd observed "a wide range of approaches, indicating that consolidating library search presents ongoing challenges." 22 In a 2011 OCLC report, Prescott and Erway identified a number of technical solutions to providing single search applications in cultural institutions, including single systems, central repositories, federated search, and central indexes. ${ }^{23}$ The variety of strategies employed by libraries to present and architect search indicates both the strong desire among libraries to get search and discovery right, and the complexity and difficulty of doing so. Swanson and Green concluded that a library website should "provide an understanding of the content, services, and tools that the site provides. This is a different task than that of Google." ${ }^{24}$ It is also challenging. Library search and discovery environments must not only 
provide useful results for a wide range of information needs; they must also help users differentiate between kinds of resources.

To provide information that may be useful for thinking about and designing the academic library search environment, this study examines two semesters of search log data generated by the NCSU Libraries' unified search application, QuickSearch. Not only is this application the default search box on the libraries' home page, it also combines results from a wider than usual range of library resources. Using these data, we will show that: our understanding of library search must be broader than article and catalog searching; analyzing and optimizing for the most frequent queries can improve the search experience for large numbers of users; and ongoing evaluation and incremental enhancement can help ensure library search applications make the best use of new technologies as user expectations and needs evolve.

\section{Literature Review}

Teague-Rector and Ghaphery captured use data of their production search interface at Virginia Commonwealth University to study how the position, screen real estate, and search target selector method (drop-down menus versus tabs) affected use of the search box. ${ }^{25}$ They found a dramatic increase in use of the search box when it was positioned centrally on the home page and given increased screen real estate. Additionally, they found that users tended to select a search target other than the default (the catalog in their designs) more frequently with the tabbed design than with the drop-down menu design. With the tabbed design, they reported that the default catalog target was used most frequently ( $60.5 \%$ of the time), followed by the articles target $(20.6 \%)$, journal titles $(16.5 \%)$, and website search $(2.3 \%)$. They also noted that a large number $(19 \%)$ of searches in the default catalog search target were full-citation searches for either articles or books. Their study calls for a more detailed analysis of search terms to help identify how users expect library search applications to perform.

Gross and Sheridan conducted a usability study at Edith Cowan University Library that examined how Summon was used by students for common library search tasks. ${ }^{26}$ The researchers wanted to determine both whether students used the search box for the assigned tasks and whether they faced any difficulties using the search tool. Summon was positioned as the primary search box on the library's home page for the study. They found that students used the single search box for 80 percent of the assigned tasks. However, the tasks given to students were limited to ones that could be successfully answered using Summon's index, such as locating a journal article about a general subject. The study found that, while students found it easy to retrieve results using the search application, they struggled to understand the results.

In a usability study of the website for the library at the University of Illinois, Augustine and Greene noted that students seemed drawn to the website's search functionality even for tasks that were beyond its capabilities. ${ }^{27}$ Similarly, in a usability study of the Moraine Valley Community College Library website, Swanson and Green found that their single search box excelled when students were looking for book titles and articles but failed when students attempted to use it to find information that was not included in the search target's index, such as information about upcoming library events. ${ }^{28}$ They concluded that a single search box may make the website more challenging to use for some informationseeking tasks.

The methodology employed by this study, transaction log analysis, has a long history as an analysis tool for library information systems. Transaction log analysis is the use of server logs that record user activity on an information system to learn more about how that system is used. According to Kurth, shortcomings 
of transaction $\log$ analysis include that the logs only record what users do, making it difficult or impossible to measure factors such as emotions and satisfaction using this technique. ${ }^{29}$ Additionally, Kurth notes that the large amount of data generated by some systems can be onerous to process and evaluate. ${ }^{30}$ However, logs lend themselves to programmatic processing, making it possible to analyze a large quantity of data about real-world use. This has led others to argue that the potentially large sample size and the nonintrusive data collection method make transaction log analysis valuable for understanding how people use systems. ${ }^{31}$ This study differs from typical transaction log studies, which generally use standard web server logs, because we use an application-specific log file designed to measure particular aspects of QuickSearch use.

\section{Background}

NC State University is a large research university in Raleigh, North Carolina, with strengths in science, technology, engineering, and mathematics. The NCSU Libraries serves about 24,000 undergraduate students, 9,000 graduate students, and 8,000 faculty and staff. This study uses data generated from use of a homegrown, combined search application called QuickSearch.

QuickSearch was developed in-house and first deployed in August 2005 as part of a major redesign of the NCSU Libraries website. The project goal was both simple and ambitious: to provide users with a unified search interface to everything the library has to offer. Although the design of the tool has evolved over the years, the goal has remained the same.

The ambitious scope of the QuickSearch project was influenced strongly by the findings of an internal log analysis study completed in 2005. Prior to QuickSearch, the NCSU Libraries website search functionality was powered by Google's free domain-specific search service, a commonly used library web- site search solution at the time. To better understand how users were searching the library website, NCSU Libraries staff captured over a year's worth of search queries sent to the Google-hosted service and stored them in an anonymized log file. The log revealed that users searched for a variety of information resources that were poorly represented in Google's index of the website. The log was replete with queries for book titles, article titles, author names, journal titles, named article databases, and general subject searches. Although our library provided access to one or more specialized search tools that were well suited for each of these search needs, we could not provide access to all of these resources in a unified search interface. Thus, QuickSearch was born from a desire to simplify the library search experience for our users. The logs indicated latent demand for such a service.

The goal of the QuickSearch project was not to replace all of our specialized discovery tools. Our ambition was to create a useful and usable single search box interface to the library that would direct users to the appropriate library discovery tool, collection, or resource for their search. The implementation accomplishes this by combining search results from many specialized search tools into a single search results screen and directing users out to dedicated search tools as needed. The first version of QuickSearch, deployed in August 2005, included a custom index of the library website, a custom "best bets" index of commonly searchedfor library resources, a locally developed subject recommender service for finding databases, an integrated frequently asked questions (FAQ) service, and outbound hyperlinks to other specialized discovery tools such as the library catalog. We have tracked and monitored the use of the QuickSearch tool on an ongoing basis since its initial deployment and have leveraged this use data to prioritize future enhancements. Over the years, we have expanded the number of library search targets integrated within the QuickSearch 


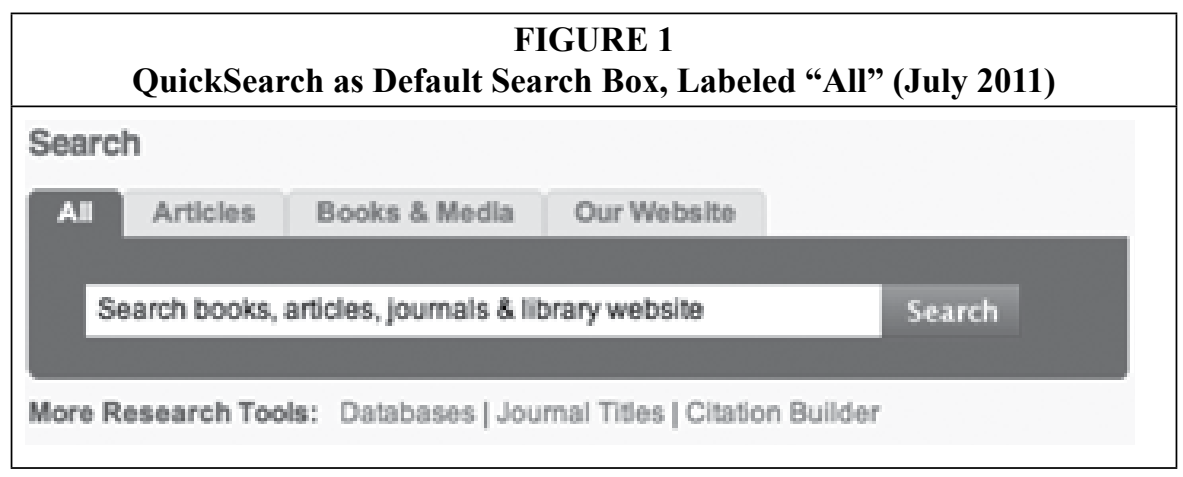

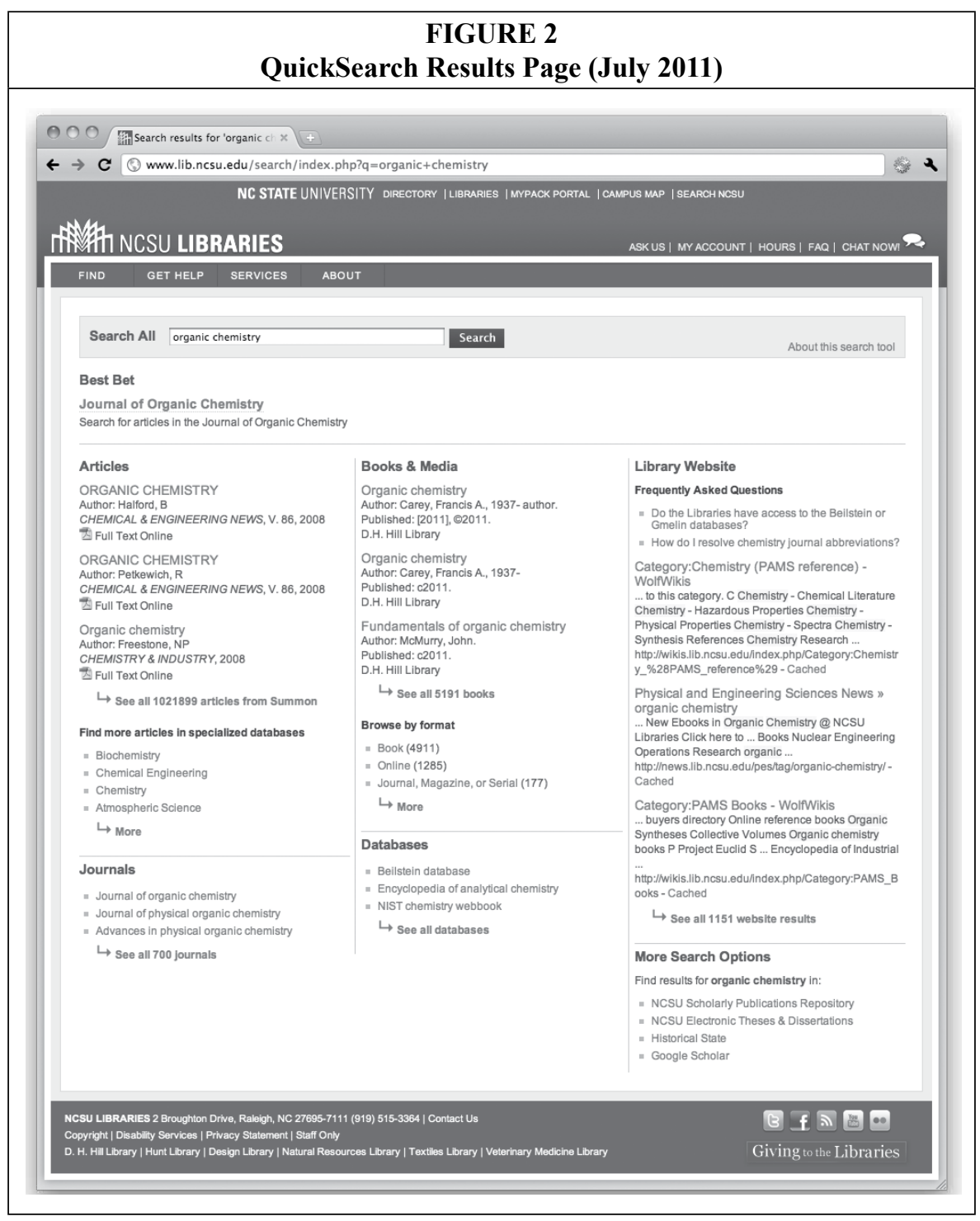


environment to include catalog search results, journal title matches, database title matches, and full-text article search results, based on observed demand for these content categories.

As part of a redesign of the NCSU Libraries website that was launched in August 2010, we made significant changes to the QuickSearch interface. QuickSearch features a "bento-box" results screen that presents dynamic results from multiple systems in different regions of the screen.
Its three-column layout prioritizes the placement of best bets, articles, and cata$\log$ results (see figure 2). Results appear in modules, sections of the results page dedicated to particular resources. For instance, best bets and spelling corrections appear at the top of the page (see figure 3, module A), article results appear on the left (see figure 3, module B), and catalog results appear in the center column (see figure 3, module C). Aside from module A, which presents a single result, the other modules

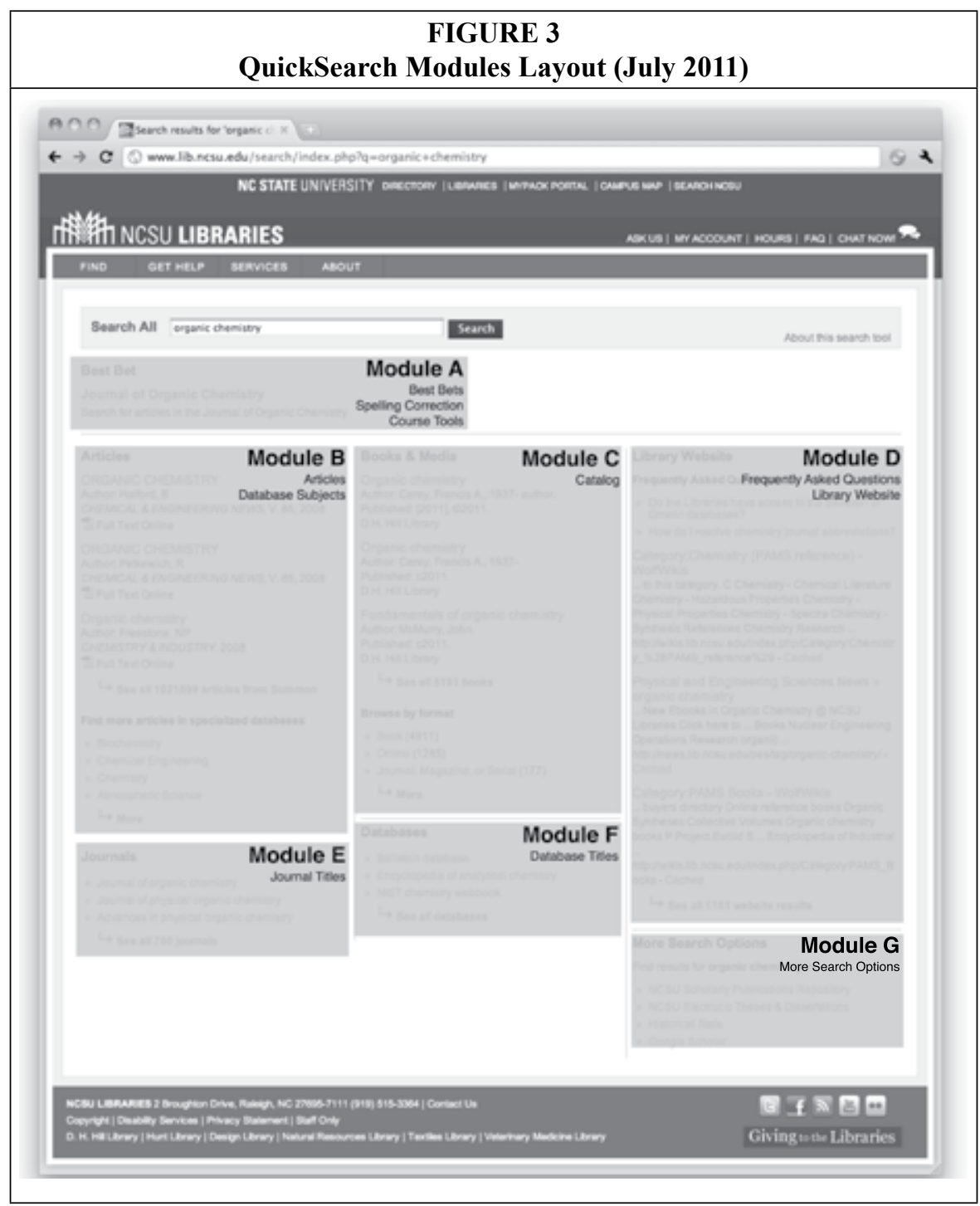


generally show as many as three results each, if available. As part of the 2010 website redesign, QuickSearch became the default search tab (labeled "All") within a four-tab search box on the library home page (see figure 1), as well as the search box integrated into global navigation on subpages of the library website. ${ }^{32}$

Several other libraries, including Villanova; University of California, San Francisco; University of Michigan; and University of Virginia, have developed similar search interfaces that combine results from multiple systems in an attempt to guide searchers to appropriate resources. Although they vary in appearance, they share a strategy of providing dynamic results from multiple sources.

\section{Methodology}

In January 2010, we implemented custom logging software that generates an anonymized transaction log of all search queries and hyperlink selections in QuickSearch. The prominent placement of the QuickSearch application's search box on the library's home page makes this a promising data set for understanding how library users search from a prominently featured default search box.
The QuickSearch log grows continuously and contains a record of every transaction handled by the application. The log records two kinds of transactions in the same log file. Every time someone uses QuickSearch to conduct a search, a "SEARCH" log entry is generated. This entry contains a Unix timestamp, human-readable date and time, the type of transaction (in this case, "SEARCH"), the query terms entered, and the referring page (see table 1). The second kind of transaction recorded by the $\log$ is a "CLICK" that records the selection of a hyperlink from the results page. In this case, the log records a tag that specifies the QuickSearch module that contained the link that was selected (for instance, "CAT" for catalog) as well as the specific link selected within that module (such as "RES_1," the first item link; see table 2). This log provides rich information about user search behavior as well as a means to continually monitor the performance of the application.

This study presents data from two complete semesters of QuickSearch use, fall 2010 (August 18, 2010, to December 18, 2010) and spring 2011 (January 10, 2011, to May 14, 2011). Unless otherwise

\begin{tabular}{|l|l|l|l|l|l|}
\hline \multicolumn{7}{|c|}{ TABLE 1 } \\
Custom Search Log \\
\hline Timestamp & Date & Time & Type & Query & Referring Page \\
\hline 1305581734 & $2011-05-16$ & $17: 35: 34$ & SEARCH & $\begin{array}{l}\text { web + of } \\
\text { + science }\end{array}$ & $\begin{array}{l}\text { http://www.lib. } \\
\text { ncsu.edu/ }\end{array}$ \\
\hline 1305581772 & $2011-05-16$ & $17: 36: 12$ & SEARCH & $\begin{array}{l}\text { ultrapure } \\
\text { + water }\end{array}$ & $\begin{array}{l}\text { http://www.lib. } \\
\text { ncsu.edu/journals/ }\end{array}$ \\
\hline 1305581784 & $2011-05-16$ & $17: 36: 24$ & SEARCH & plotter & $\begin{array}{l}\text { http://www.lib. } \\
\text { ncsu.edu/ }\end{array}$ \\
\hline
\end{tabular}

TABLE 2

Custom Click Log

\begin{tabular}{|l|l|l|l|l|l|}
\hline Timestamp & Date & Time & Type & Module & Result Selected \\
\hline 1305581736 & $2011-05-16$ & $17: 35: 36$ & CLICK & BB & webofscience \\
\hline 1305581804 & $2011-05-16$ & $17: 36: 44$ & CLICK & LWP & RES_1 \\
\hline 1305581826 & $2011-05-16$ & $17: 37: 06$ & CLICK & CAT & RES_1 \\
\hline
\end{tabular}


How Users Search the Library from a Single Search Box 235

\begin{tabular}{|l|c|c|c|}
\hline \multicolumn{4}{|c|}{ TABLE 3 } \\
\hline & Fall 2010 & Spring 2011 & Overall \\
\hline Searches & 357,318 & 381,862 & 739,180 \\
\hline Clicks & 315,738 & 339,650 & 655,388 \\
\hline Searches / Day & 2,953 & 3,007 & 2,981 \\
\hline Clicks / Day & 2,609 & 2,674 & 2,643 \\
\hline
\end{tabular}

specified, the data presented is the aggregate of log data for both semesters.

\section{Results}

\section{Overall}

In all, 739,180 searches were conducted in QuickSearch during the fall 2010 and spring 2011 semesters. During the same period, 655,388 hyperlinks were selected from the QuickSearch results interface (see table 3).

As shown in figure 4, the articles and catalog modules account for most of the hyperlinks selected, attracting 76.69 percent of combined use. Individually, other modules are used much less fre- quently, but altogether they account for more than 23 percent of QuickSearch use. Of these other modules, best bets $(7.81 \%)$ and journal titles $(5.53 \%)$ are the most frequently used. Spelling correction is used fairly frequently, accounting for 2.74 percent of clicks in QuickSearch. The library website search module is used less frequently $(2.14$ percent of QuickSearch hyperlink selections), although best bets and FAQs absorb some traffic from this module. Database titles are underrepresented, since this module was added late in the sample period (implemented February 24, 2011).

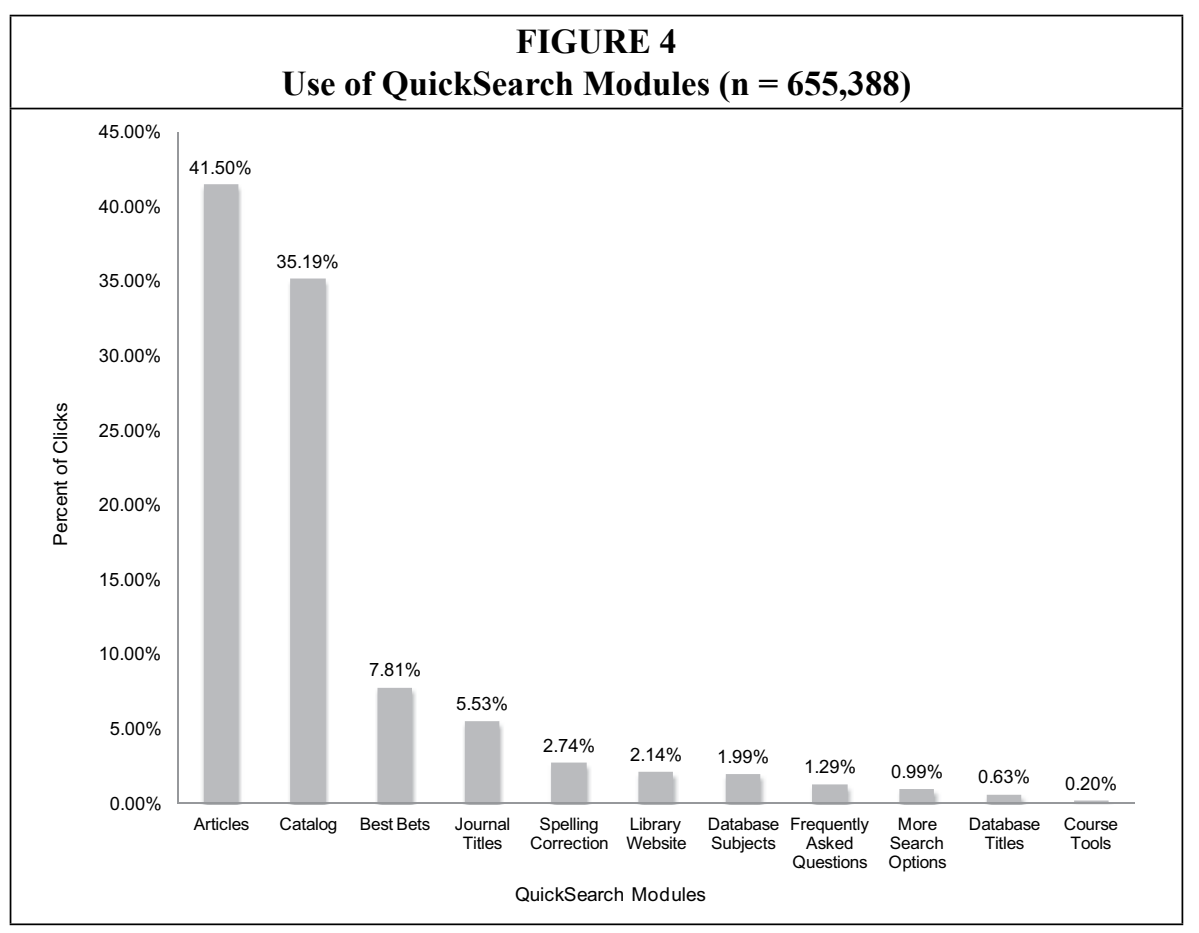




\begin{tabular}{|l|c|c|}
\hline \multicolumn{3}{|c|}{ TABLE 4 } \\
Use of Item Links and Links to \\
Additional Results \\
\hline & $\begin{array}{c}\text { Item } \\
\text { Link }\end{array}$ & $\begin{array}{c}\text { Additional } \\
\text { Results }\end{array}$ \\
\hline Articles & $69.58 \%$ & $30.42 \%$ \\
\hline Catalog & $62.79 \%$ & $37.21 \%$ \\
\hline Library Website & $89.89 \%$ & $10.11 \%$ \\
\hline
\end{tabular}

Articles and Catalog Module Use Patterns

The articles, catalog, and library website modules each display up to three result links, as well as a link to "See all results," which leads to the full list of results for the module. In addition, the catalog module contains links to view results by format (such as "Book," "Videos and DVDs"). Links in QuickSearch can be divided roughly into two categories: hyperlinks that go directly to a resource (for example, an item link that goes to a specific journal article or a catalog detail page for a specific book) and hyperlinks that show additional results in the native results interface (for instance, the Summon results interface or the catalog results interface), typically through a "See all results" link.
In the articles, catalog, and library website modules, the hyperlinks that lead directly to specific items are used more frequently than hyperlinks to the full list of results (see table 4).

\section{Use Patterns over Time}

Since we began custom logging in January of 2010, the catalog is the most used module from the start of the semester until the fourth week, when use of the articles module surpasses it (see figures 5 and 6). The change in use of other modules during the course of the semester is less remarkable, with predictable decreases during breaks.

Overall use of the journal titles module increased in spring 2011. This increase occurred after we switched from using a begins-with search to a keyword search for this module.

\section{Query Terms}

Fourteen of the top twenty most queried search terms in fall 2010 remained in the top twenty list in spring 2011, with small fluctuations in rank (see tables 5 and 6). Many of the top search terms are research databases, such as "web of science," "js-

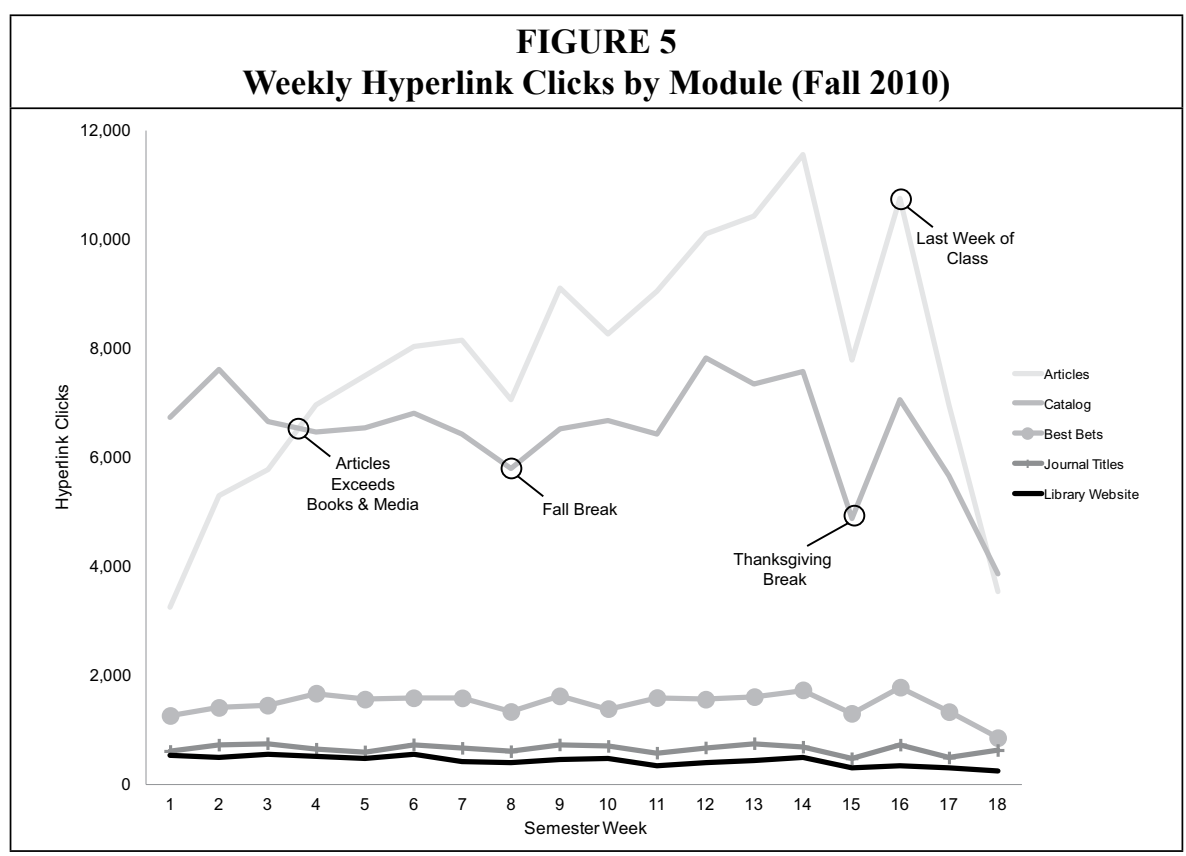




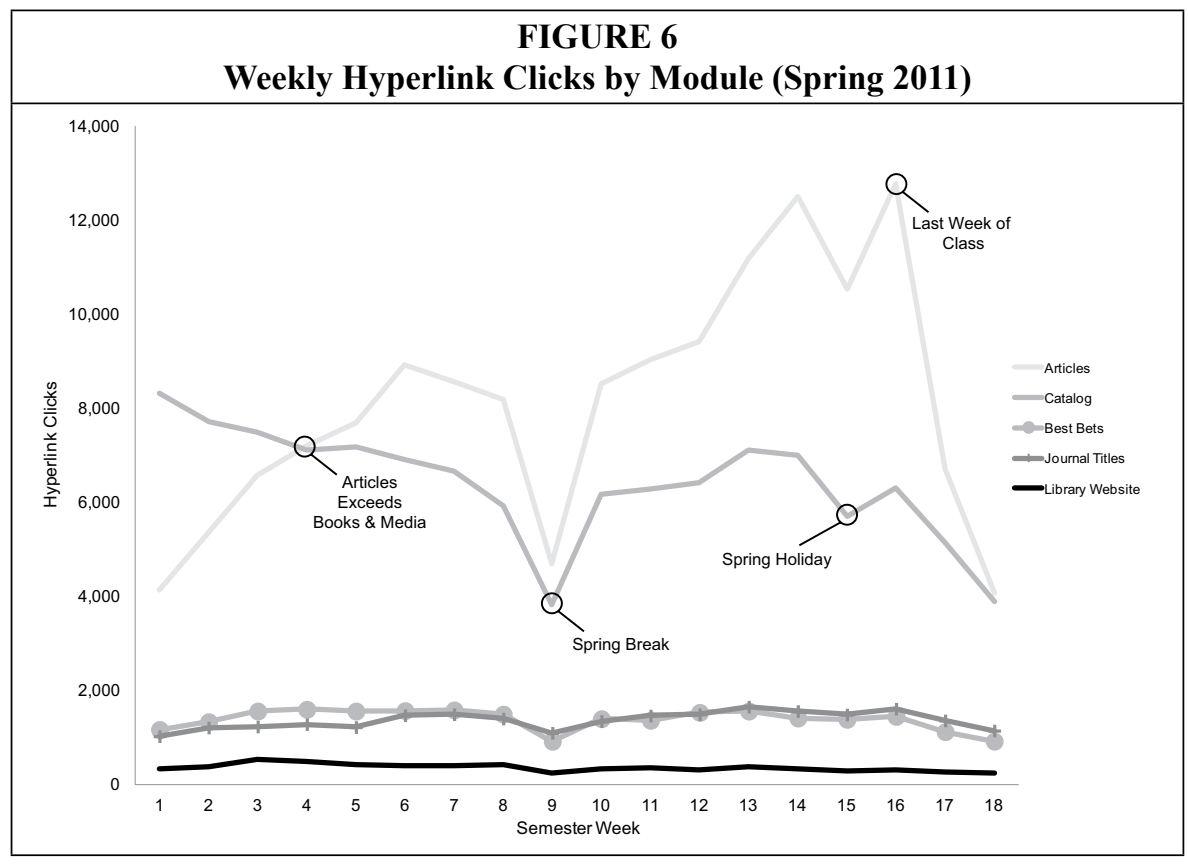

tor," and "google scholar." Others are popular journal titles, such as "science" and "harvard business review." The rest are a mix of library services and tools, such as "citation builder" and "gis," as well as administrative information about petitioning fines. Although the long tail of the query log contains many more searches for author names, book titles, article titles, and general subject searches, these tend to be more heterogeneous and therefore do not appear among the most frequent searches.

Additionally, the most frequent queries make up a disproportionately large number of QuickSearch searches (see table $7)$. For instance, to analyze 10 percent of all searches on the site (nearly 38,000 individual queries), we can look at just the top 153 most popular queries in the spring 2011 semester. To manually review the next 10 percent would be impractical, as we would have to then examine over 2,000 unique queries.

\section{Discussion}

The story of library search and discovery is about articles, the catalog, and everything else. While the articles and catalog modules are used most often in QuickSearch, a significant amount (about $23 \%$ ) of activity occurs in other modules (see figure 4). Additionally, many of the most frequent queries are not well served by the catalog and articles modules. The top twenty most frequent query terms, which account for more than 5 percent of all searches, consist primarily of database titles, journal titles, and searches for administrative information ("petition") and library services ("course reserves," "gis"). This makes us think that a single search box must either make it transparent to users what it searches or must be able to guide users appropriately to information and resources beyond articles and the catalog.

\section{Dynamic Results Drive Traffic}

As we have expanded QuickSearch over the years, we have observed that dynamic search results drive traffic. In the early days of QuickSearch, we provided a static link to search the catalog from the results page. When the catalog results could be queried via a locally developed API, we 


\begin{tabular}{|c|c|c|c|c|}
\hline \multicolumn{5}{|c|}{$\begin{array}{c}\text { TABLE } 5 \\
\text { Top } 20 \text { Most Frequent Queries Fall } 2010\end{array}$} \\
\hline Rank & Query & Count & \% of Total & Cumulative \% \\
\hline 1 & & 4,854 & $1.35 \%$ & $1.35 \%$ \\
\hline 2 & web + of + science & 4,181 & $1.16 \%$ & $2.52 \%$ \\
\hline 3 & refworks & 1,948 & $0.54 \%$ & $3.06 \%$ \\
\hline 4 & citation+builder & 1,627 & $0.45 \%$ & $3.51 \%$ \\
\hline 5 & jstor & 1,506 & $0.42 \%$ & $3.93 \%$ \\
\hline 6 & google + scholar & 1,472 & $0.41 \%$ & $4.34 \%$ \\
\hline 7 & pubmed & 778 & $0.22 \%$ & $4.56 \%$ \\
\hline 8 & petition & 673 & $0.19 \%$ & $4.74 \%$ \\
\hline 9 & ieee & 608 & $0.17 \%$ & $4.91 \%$ \\
\hline 10 & naxos & 601 & $0.17 \%$ & $5.08 \%$ \\
\hline 11 & etd & 535 & $0.15 \%$ & $5.23 \%$ \\
\hline 12 & course+reserves & 386 & $0.11 \%$ & $5.34 \%$ \\
\hline 13 & science & 379 & $0.11 \%$ & $5.44 \%$ \\
\hline 14 & gis & 373 & $0.10 \%$ & $5.55 \%$ \\
\hline 15 & tripsaver & 363 & $0.10 \%$ & $5.65 \%$ \\
\hline 16 & academic + search + premier & 356 & $0.10 \%$ & $5.75 \%$ \\
\hline 17 & harvard+business+review & 352 & $0.10 \%$ & $5.84 \%$ \\
\hline 18 & eric & 345 & $0.10 \%$ & $5.94 \%$ \\
\hline 19 & citation & 337 & $0.09 \%$ & $6.03 \%$ \\
\hline 20 & thesis & 329 & $0.09 \%$ & $6.13 \%$ \\
\hline
\end{tabular}

began including these results in QuickSearch and subsequently observed a significant increase in the use of QuickSearch for catalog searches. We observed a similar increase in use when we changed the journal titles module from using a begins-with search to a keyword search (see figures 5 and 6). Small changes to how results are retrieved can significantly impact use.

\section{Satisfy Common Queries with Best Bets}

Some of the most common queries are handled poorly by algorithmic retrieval methods. Louis Rosenfeld notes in his book, Search Analytics for Your Site, that a small amount of effort spent making sure the top queries perform well can improve the search experience for a significant number of users. ${ }^{33}$

The most frequently occurring queries to QuickSearch have proven to be predictable over time. Examples include: popular databases such as JSTOR and Web of Science; individual journals such as Science and Nature; useful web tools such as RefWorks and the Citation Builder (a tool developed at the NCSU Libraries); and services such as Tripsaver, the brand name of our interlibrary loan and document delivery service (see tables 5 and 6). We focus on the top 100 most frequent queries to develop a small set of search results, best bets, that are triggered by keywords that we define. It is both 
feasible and practical to examine the top 100 most popular queries, because they account for a relatively large portion of the overall queries (just under 10 percent in spring 2011; see table 7). This strategy has proven to be successful; the best bets module is the most frequently used in QuickSearch after articles and the catalog (see figure 4).

\section{Continual Evaluation}

QuickSearch has changed significantly since its launch in 2005. Its evolution has been characterized by ongoing, incremental improvement as well as more occasional substantial changes. A small product team of four to five digital library and public services librarians has managed this evolution.

The tool has evolved incrementally because of the team's regular evaluation of use data. Prior to implementing custom logging in January 2010, the team used server logs and standard web analytics tools to track usage of QuickSearch. Each semester, a team member prepares a detailed report on the previous semester's use. We use the data to evaluate the performance of different modules, identify what works well, and areas for improvement. For example, in 2006, we noticed a "Quick Article Search" function receiving heavy use, so we gave it a more prominent place in the interface. We also

\begin{tabular}{|c|c|c|c|c|}
\hline \multicolumn{5}{|c|}{$\begin{array}{c}\text { TABLE } 6 \\
\text { Top } 20 \text { Most Frequent Queries Spring } 2011\end{array}$} \\
\hline Rank & Query & Count & $\%$ of Total & Cumulative \% \\
\hline 1 & web+of+science & 4,196 & $1.11 \%$ & $1.11 \%$ \\
\hline 2 & & 4,048 & $1.07 \%$ & $2.17 \%$ \\
\hline 3 & refworks & 2,192 & $0.58 \%$ & $2.75 \%$ \\
\hline 4 & google+scholar & 1,630 & $0.43 \%$ & $3.18 \%$ \\
\hline 5 & citation+builder & 1,122 & $0.30 \%$ & $3.48 \%$ \\
\hline 6 & jstor & 1,016 & $0.27 \%$ & $3.75 \%$ \\
\hline 7 & ieee & 823 & $0.22 \%$ & $3.96 \%$ \\
\hline 8 & pubmed & 782 & $0.21 \%$ & $4.17 \%$ \\
\hline 9 & petition & 767 & $0.20 \%$ & $4.37 \%$ \\
\hline 10 & etd & 578 & $0.15 \%$ & $4.53 \%$ \\
\hline 11 & morningstar & 560 & $0.15 \%$ & $4.67 \%$ \\
\hline 12 & naxos & 553 & $0.15 \%$ & $4.82 \%$ \\
\hline 13 & digital+repository & 420 & $0.11 \%$ & $4.93 \%$ \\
\hline 14 & science & 415 & $0.11 \%$ & $5.04 \%$ \\
\hline 15 & gis & 404 & $0.11 \%$ & $5.15 \%$ \\
\hline 16 & nature & 395 & $0.10 \%$ & $5.25 \%$ \\
\hline 17 & tripsaver & 353 & $0.09 \%$ & $5.34 \%$ \\
\hline 18 & scifinder & 333 & $0.09 \%$ & $5.43 \%$ \\
\hline 19 & science+direct & 325 & $0.09 \%$ & $5.52 \%$ \\
\hline 20 & ieee+xplore & 302 & $0.08 \%$ & $5.60 \%$ \\
\hline
\end{tabular}




\begin{tabular}{|l|c|c|c|}
\hline \multicolumn{5}{|c|}{ TABLE 7 } \\
\hline Distribution of Unique Queries (Spring 2011) (N=379,080) \\
\hline 1 & Cumulative \% & Count & Query \\
\hline 14 & $1.11 \%$ & 4,196 & web of science \\
\hline 153 & $5.04 \%$ & 415 & science \\
\hline 2,213 & $10.00 \%$ & 63 & ereserve \\
\hline 9,044 & $20.00 \%$ & 9 & journal of environmental education \\
\hline
\end{tabular}

make changes to QuickSearch when the availability of new tools provides opportunities for improvement. For example, in 2005 and 2006, the only way QuickSearch was able to offer access to the Libraries' catalog was via a link to the catalog's result interface. In 2007, a catalog API became available, so we developed a catalog module that integrates title matches in the QuickSearch interface. Similarly, in 2009 we added article results to QuickSearch after acquiring the Summon product from SerialSolutions. Ongoing evaluation of use data and incremental improvement keep the application up-to-date as technologies and user expectations change.

\section{Conclusion}

Academic library user search behavior may vary among institutions. However, there are general lessons to be learned from the analysis of QuickSearch logs at the NCSU Libraries. One lesson is that library search is about more than articles and the catalog. About 23 percent of use of QuickSearch took place outside either the catalog or articles modules, indicating that NCSU Library users attempt to access a wide range of information from the single search box.

Ongoing evaluation of user search behavior using log data can uncover opportunities for improving search. The most frequently occurring queries may reveal latent demand for resources and hints about whether the search target meets user expectations. Additionally, ensuring that the most frequent queries provide good results can improve the search experience for large numbers of users.

A single search box communicates confidence to users that our search tools can meet their information needs from a single point of entry. If libraries are to provide viable single search options, they will need to understand how users search the library from a single search box, and evaluate how well different single search implementations perform. More quantitative and qualitative studies of how users search and expect to search the library in a single search environment are needed.

New information resources, such as discovery platforms, have the potential to improve the user experience of library search, but only if we understand how to integrate these tools with other services and information resources so that they are useful and understandable. The library search experience must be designed carefully to balance user needs and expectations with the capabilities of library information systems.

\section{Notes}

1. Troy A. Swanson and Jeremy Green, "Why We Are Not Google: Lessons from a Library Website Usability Study," Journal of Academic Librarianship 37, no. 3 (Mar. 2011): 222-29.

2. Lorcan Dempsey, "Reconfiguring the Library Systems Environment," portal: Libraries and the Academy 8, no. 2 (2008): 111-20.

3. Kristin Antelman, Emily Lynema, and Andrew K. Pace, "Toward a Twenty-First Century Library Catalog," Information Technology and Libraries 25, no. 3 (2006): 128-39. 
4. Ian Gibson, Lisa Goddard, and Shannon Gordon, “One Box to Search Them All: Implementing Federated Search at an Academic Library," Library Hi Tech 27, no. 1 (2009): 118-33; John Boyd, Marian Hampton, Patricia Morrison, Penny Pugh, and Frank Cervone, "The One-Box Challenge: Providing a Federated Search That Benefits the Research Process," Serials Review 32, no. 4 (Dec. 2006): 247-54; Doris Small Helfer and Jina Choi Wakimoto, "Leading Libraries: Metasearching: The Good, the Bad, and the Ugly of Making It Work in Your Library," Searcher 13, no. 2 (2005): 40-41.

5. Dennis Warren, "Lost in Translation: The Reality of Federated Searching," Australian Academic \& Research Libraries 38, no. 4 (2007): 258-70.

6. William J. Frost, “BackTalk: Do We Want or Need Metasearching?” Library Journal, (2004), available online at www.libraryjournal.com/article/CA405394.html, accessed 7 June 2011

7. Frank Cervone, "What We've Learned from Doing Usability Testing on OpenURL Resolvers and Federated Search Engines," Computers in Libraries 25, no. 9 (2005) 10-14.

8. Warren, "Lost In Translation."

9. Doug Way, "The Impact of Web-scale Discovery on the Use of a Library Collection," Serials Review 36, no. 4 (Dec. 2010): 214-20; Marshall Breeding, "The State of the Art in Library Discovery 2010," Computers in Libraries 30, no. 1 (2010): 31-34; Jeff Wisniewski, "Web Scale Discovery: The Future's So Bright I Gotta Wear Shades," Online 34, no. 4 (2010): 55-58.

10. Way, "The Impact of Web-scale Discovery."

11. Ibid.

12. Abe Crystal, "NCSU Libraries Summon User Research: Findings and Recommendations" (2011), available online at http://www.lib.ncsu.edu/documents/userstudies/2010summon/ Summon-usability.docx, accessed 21 March 2013; Wisniewski, "Web Scale Discovery."

13. Julia Gross and Lutie Sheridan, "Web Scale Discovery: The User Experience," New Library World 112, no. 5/6 (2011): 236-47; Swanson and Green, "Why We Are Not Google."

14. Wisniewski, "Web Scale Discovery."

15. Susan Teague-Rector and James Ghaphery, "Designing Search: Effective Search Interfaces for Academic Library Web Sites," Journal of Web Librarianship 2, no. 4 (2008): 479-92.

16. Ibid.

17. Swanson and Green, "Why We Are Not Google."

18. Susan Augustine and Courtney Greene, "Discovering How Students Search a Library Web Site: A Usability Case Study," College E Research Libraries 63, no. 4 (2002): 354-65.

19. Lorcan Dempsey, "Discovery Layers: Top Tech Trends 2," Lorcan Dempsey's Weblog on Libraries, Services, and Networks (blog), July 4, 2010, available online at http://orweblog.oclc.org/ archives/002116.html, accessed 2 June 2011.

20. James Ghaphery, Susan Teague-Rector, and Sam Byrd, "Kinda Just Like Google: Presence and Variety of Search Options on Library Homepages," Against the Grain 20, no. 3 (June 2008): 18-24.

21. Teague-Rector and Ghaphery, "Designing Search."

22. Ghaphery, Teague-Rector, and Byrd, "Kinda Just Like Google."

23. Leah Prescott and Ricky Erway, "Single Search: The Quest for the Holy Grail," Dublin, Ohio: OCLC Research, (2011): 12-17, available online at www.oclc.org/research/publications/ library/2011/2011-17.pdf, accessed 23 August 2011.

24. Swanson and Green, "Why We Are Not Google."

25. Teague-Rector and Ghaphery, "Designing Search."

26. Gross and Sheridan, "Web Scale Discovery."

27. Augustine and Greene, "Discovering How Students Search a Library Web Site."

28. Swanson and Green, "Why We Are Not Google."

29. Martin Kurth, "The Limits and Limitations of Transaction Log Analysis," Library Hi Tech 11, no. 2 (1993): 98-104.

30. Ibid.

31. Bernard J. Jansen, "Search Log Analysis: What It Is, What's Been Done, How to Do It," Library E Information Science Research 28, no. 3 (Autumn 2006): 407-32; Christine L. Borgman, Sandra G. Hirsh, and John Hiller, "Rethinking Online Monitoring Methods for Information Retrieval Systems: From Search Product to Search Process," Journal of the American Society for Information Science 47, no. 7 (1996): 568-83.

32. Susan Teague-Rector, Angela Ballard, and Susan K. Pauley, "The North Carolina State University Libraries Search Experience: Usability Testing Tabbed Search Interfaces for Academic Libraries," Journal of Web Librarianship 5, no. 2 (2011): 80-95.

33. Louis Rosenfeld, "Search Analytics for Your Site," Brooklyn, NY: Rosenfeld Media, (2011): 19-21, 126-27. 

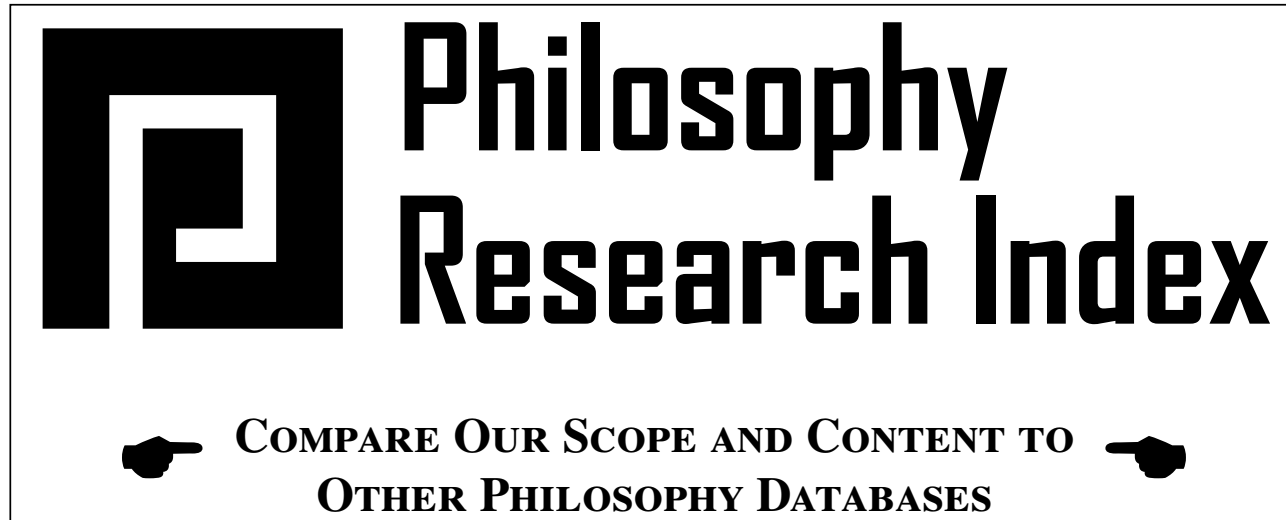

The Philosophy Research Index is an indexing database of bibliographic information on articles, books, reviews, dissertations, and other documents in philosophy. It uses the best available technology to increase bibliographic coverage of the known philosophical literature in several western languages. Coverage includes current and recent materials, as well as older literature back to the 15 th century. The largest portion of this coverage is in English, but the databae contains listings of items in many other languages. Current listings and features include:

\section{Over 1.2 Million Bibliographic Records}

- 800 journals and series (and growing)

- coverage of materials in 30 languages

- multiple search and browse options

- facted search results and timeline

- save/export search results
- automatic translation function

- metasearch of all PDC resources

- OpenURL ready

- direct links to JSTOR

- monthly updates

The metasearch also allows PRI users to search all fulltext documents in our E-Collection and all listings in our International Directory of Philosophy.

The translation function helps users combine all results into English, and social networking functionality facilitates information sharing. The database is OpenURL ready and an extended librarians' view is available for each citation.

This database is building bibliographic coverage of ALL philosophical literature.

\section{Free Trials}

\section{http://secure.pdenet.org/pri}

\section{Institutions \$1500/year}

IP authentication, COUNTER-compliant usage statistics

\section{Philosophy Documentation Center}

P.O. Box 7147, Charlottesville, Virginia 22906-7147 - USA

Tel. 434.220.3300

Toll-Free: 800.444 .2419 (US \& Canada)

order@pdcnet.org www.pdcnet.org 